\title{
Epidemiological Study of Features of Primary Dentition Occlusion in Iraqi Preschool
}

\author{
Kids sample \\ Jamal KM \\ M.Sc. Orthodontic - University of Tikrit, College of Dentistry \\ Azhar Amash \\ M.Sc. Prevention - University of Tikrit, College of Dentistry \\ Ahmed Ibrahim \\ M.Sc. Operative - University of Tikrit, College of Dentistry
}

\section{ABSTRACT}

Occlusion characteristics of the deciduous dentition plays an important responsibility in the subsequent final occlusion of the permanent teeth. Consequently, good understanding of occlusion in preschoolers is important for pediatric dentist. A total of 630 children of 3-5 years age group with complete primary dentition were examined for occlusal and canine relationship, primate spaces, physiological spacing and overbite. There is alteration in primary molar relation as age increases ,there was a significant rise in mesial step molar relation within five years age group compared to three years age group. The class I canine relation was the most predominant canine relationship, but canine relation alterations with age was not statistically significant. Larger number of the assessed children had spaced primary dentition and flush terminal plane that precede to occurrence of typical occlusion of permanent teeth.

\section{KEY WORDS}

Primary teeth features, occlusion, preschoolers.

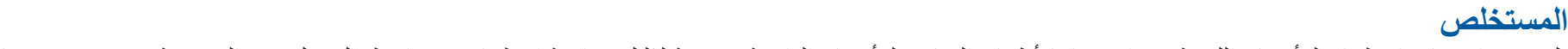

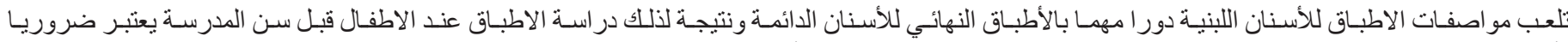

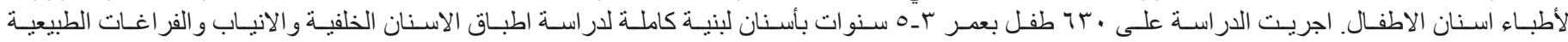

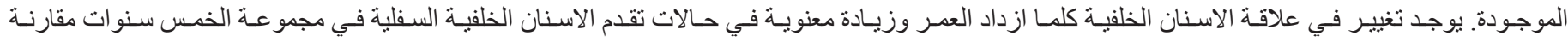

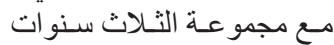

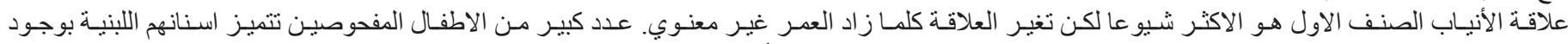

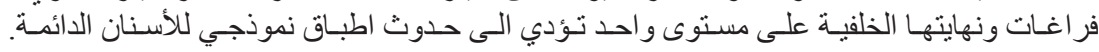

\section{INTRODUCTION}

Primary teeth occlusion plays significant roles in guiding the occlusion of permanent teeth. There is little information about the changes of occlusal pattern during primary dentition period. The recognition of normal occlusion patterns in deciduous dentition as well as the identification of morphologic changes during eruption of permanent teeth is essential for treatment planning in pediatric dentistry ${ }^{(1)}$.

Understanding of the terminal relationships variations of the primary second molars and their effect on eruption of first permanent molars is essential for interception and prevention and of malocclusions development. Canine is essential tooth to considered in the developing occlusion, since relationship of maxillary and mandibular primary canines is one of the most stable relation in deciduous dentition which influences the canine relationship in the permanent teeth $^{(2)}$.

It is usual for the second molars to have a flush terminal plane relationship and to have spacing between the teeth in the primary dentition; the initial occlusion of the first permanent molar at the time of eruption is dependent on terminal plane relation of the deciduous second molars ${ }^{(3-6)}$.

Deciduous dentition spacing plays later an principal role in the arrangement of erupting permanent dentition and establishing normal occlusion. Lack of spaces in the deciduous teeth is an representation of disproportion concerning tooth and jaw size. Prevalence of spacing in the primary dentition varies between different ethnic and populations groups ${ }^{(7-9)}$.

The distal step relationship of the primary molar teeth commonly result in Angel class II molar relation whereas smaller number of mesial step cause class III molar relation. Flush terminal plane is the most frequent relation of the primary molar teeth result in class I molar relationship ${ }^{(10)}$.

Nanda et al ${ }^{(11)}$ found that the usual occlusal pattern for the deciduous dentition were (class I and class III) molar and canine relation in Indian children. The incidence of class III molar and canine relationship increased with age, while those with class I decreased with age. Kisling and Kerbs ${ }^{(12)}$ conducted a study on occlusion in 3 year old children living in Copenhagen and found open bite much more frequently in children with maxillary overjet greater than $4 \mathrm{~mm}$. Kabue et $\mathrm{al}^{(13)}$ found that the, mesial step of the deciduous second molars was presented in $43 \%$ of the Kenyan children ,distal step occlusion in $1 \%$ and straight terminal plane was presented in $53 \%$; they concluded that more than half of the children were found to have some form of malocclusion. Valente and Mussolino ${ }^{(14)}$ assessed the distribution of open bite, overjet and overbite in deciduous dentition in Brazilian white children, and they found that the degree of open bite and overjet decreased with age. Ferreira et al ${ }^{(15)}$ concluded that the most common occlusal relation 
between primary molars and primary canines was class I in Brazilian children.

Assessment of the development of occlusion in the primary dentition considered one of the most valuable aims of pediatric and orthodontic dentistry and it is important to ensure a normal occlusion in the permanent dentition. The current study was carried out to assess the occlusal features of the deciduous dentition in Iraqi children sample.

\section{MATERIALS AND METHODS}

Six hundred and thirty children (332 boys and 298 girls) of age group of 3 to 5 years, from all nursery schools in and around the city of Tikrit were selected. The schools were randomly selected. All children, whose age was between (3-5) years, had complete set of primary dentition and healthy irrespective of socioeconomic status were selected for the study. Those children who had grossly decayed or any permanent teeth were discounted from the study, no sucking habits and no previous orthodontic treatment. The age of the child was taken from school archives. Clinical examination was done on children who had completed deciduous dentition not including any erupted permanent teeth and no extensive caries that would change the mesiodistal and incisocervical dimensions of a teeth and so influence the occlusion features. All children were examined while sitting in an upright position and biting in maximal intercuspation, using mouth mirror, pen light, millimeter rulers.

\section{Evaluation criteria}

1.Primary canine relation

- Class I: The upper primary canine cusp tip lie in same vertical plane with the lower primary canine distal surface.

- Class II: The upper primary canine cusp tip is mesial to the lower primary canine distal surface.

- Class III: The upper primary canine cusp tip is distal to the lower primary canine distal surface.

2.Terminal plane relation

- Distal step: The distal surface of the lower primary second molar is distal to the upper primary second molar distal surface in centric occlusion.

- Mesial step: The distal surface of the lower primary second molar is mesial to the upper primary second molar distal surface in centric occlusion.

- Flush terminal plane: The distal surface of upper primary second molar is in the same vertical plane in centric occlusion with the distal surface of lower primary second molar.

3.The degree of overbite was recorded in centric occlusion as

- Anterior open bite: in cases of no vertical overlap between maxillary and mandibular primary incisors.

- Edge-to edge relation between upper and lower primary incisors

- Normal: the maxillary primary central incisors covering less than or equal to $50 \%$ of lower primary incisors

- Increased: the upper primary central incisors covering more than $50 \%$ of lower primary incisors. Furthermore the physiological spaces and the primate spaces had been documented for each child in the maxillary and mandibular arches.

\section{Statistical analysis:}

All data was analyzed using the Statistical Package for Social Sciences for Windows (SPSS) software package. A chi-square test was applied to evaluate the percentages of different occlusal characters in various age groups. The significant level was set at 0.05 . Paired t-test was used to determine the differences of occlusal characteristics within the same age group.

\section{RESULTS}

Table 1 showed percentage distribution of terminal molar relationship, the age wise changes in terminal molar relationship were statistically very highly significant. Flush terminal molar relation was seen in $69.4 \%$ of subjects on right side and $69.8 \%$ on left side. Distal step was seen in $1.6 \%$ in both right and left side. The mesial step was seen in $29.7 \%$ on right side and $27.9 \%$ on left side. Girls and boys were merged in all age groups since there were no significant distinctions between them with respect to occlusion characteristics.

The percentage distribution of canine relation was class II in $4.6 \%$, class I in $91.7 \%$ and class III in $3.7 \%$ in the left side. on the right side the percentage distribution was class II in $5.7 \%$, class III in 3.3\% and class I in $91 \%$. The most frequent primary canine relation was observed to be class I relationship, no statistically significant difference was found between different age groups (Table 2).

The results of present study as shown in Table 3 indicate that $67.3 \%$ of children had normal overbite, $31.6 \%$ increased overbite, $0.8 \%$ edge to edge and $0.3 \%$ anterior open bite. The age wise changes in degree of overbite were statistically insignificant .The percentage of children with normal overbite increased from age 3 to 5 years, and from age 3 to 4 years. The increased overbite percentage decreased in 
older age group. Table 4 and Table 5 illustrated that the majority of the kids in the upper arch $89.8 \%$ and no statistically considerable difference was noticed less percentage $81 \%$ was registered in the lower arch, in the upper or lower arches between the three age while physiological spaces were found in $81.9 \%$ in groups concerning physiological and primate spaces. the upper arch and $73.2 \%$ in the lower arch.

In the present study primate spaces were observed in

TABLE 1. Percentage distribution of terminal molar relationship

\begin{tabular}{|c|c|c|c|c|c|c|}
\multirow{2}{*}{ Age } & \multicolumn{2}{c|}{ Mesial step } & \multicolumn{2}{c|}{ distal step } & \multicolumn{2}{c|}{ Flush terminal } \\
\cline { 2 - 8 } & right & left & right & left & Right & left \\
\hline 3 year & $61(24.4 \%)$ & $56(22.4 \%)$ & $3(1.2 \%)$ & $3(1.2 \%)$ & $187(74.8 \%)$ & $190(76 \%)$ \\
4 year & $78(35.4 \%)$ & $74(33.6 \%)$ & $5(2.3 \%)$ & $5(2.3 \%)$ & $142(64.5 \%)$ & $136(61.8 \%)$ \\
5 year & $48(30 \%)$ & $46(28.8 \%)$ & $2(1.2 \%)$ & $2(1.2 \%)$ & $108(67.5 \%)$ & $114(71.3 \%)$ \\
Total & $187(29.7 \%)$ & $176(27.9 \%)$ & $10(1.6 \%)$ & $10(1.6 \%)$ & $437(69.4 \%)$ & $440(69.8 \%)$ \\
\hline
\end{tabular}

For right side: $\mathrm{X} 2=\mathbf{4 4 . 7 2}, \mathrm{p}=\mathbf{0 . 0 0 6}$ (highly significant); For left side: $\mathrm{X} 2=\mathbf{4 2 . 8 1 4}, \mathrm{p}=\mathbf{0 . 0 0 7}$ (highly significant)

TABLE 2. Primary canine relationship

\begin{tabular}{|c|c|c|c|c|c|c|c|}
\hline Age & \multicolumn{2}{c}{ Class I } & \multicolumn{2}{c|}{ Class II } & \multicolumn{2}{c|}{ Class III } & Total \\
\hline & right & left & right & left & Right & left & \\
\hline 3 year & $225(90 \%)$ & $230(92 \%)$ & $14(5.6 \%)$ & $12(4.8 \%)$ & $9(3.6 \%)$ & $10(4 \%)$ & 250 \\
4 year & $202(91.8 \%)$ & $204(92.7 \%)$ & $12(5.5 \%)$ & $9(4.1 \%)$ & $6(2.7 \%)$ & $7(3.2 \%)$ & 220 \\
5 year & $146(91.3 \%)$ & $144(90 \%)$ & $10(6.3 \%)$ & $8(5 \%)$ & $6(3.8 \%)$ & $6(3.8 \%)$ & 160 \\
Total & $573(91 \%)$ & $578(91.7 \%)$ & $36(5.7 \%)$ & $29(4.6 \%)$ & $21(3.3 \%)$ & $23(3.7 \%)$ & 630 \\
\hline
\end{tabular}

For right side: $X^{2}=8.56, p=0.086$ (not significant); For left side: $X^{2}=9.71, p=0.077$ (not significant)

TABLE 3. Degree of overbite

\begin{tabular}{|c|c|c|c|c|c|}
\hline Age & Normal & Edge to edge & Increased & Anterior open bite & Total \\
\hline 3 year & $162(64.8 \%)$ & $\mathbf{2}(0.8 \%)$ & $\mathbf{8 6}(34.4 \%)$ & $\mathbf{0}$ & 250 \\
\hline year & $154(70 \%)$ & $\mathbf{0}$ & $\mathbf{6 6}(30 \%)$ & $\mathbf{0}$ & 220 \\
\hline 5 year & $108(67.5 \%)$ & $\mathbf{3}(1.9 \%)$ & $\mathbf{4 7}(29.4 \%)$ & $\mathbf{2}(1.3 \%)$ & 160 \\
\hline Total & $424(67.3 \%)$ & $\mathbf{5}(0.8 \%)$ & $\mathbf{1 9 9}(31.6 \%)$ & $\mathbf{2}(0.3 \%)$ & 630 \\
\hline
\end{tabular}

$\mathrm{X} 2=10.72, \mathrm{p}=\mathbf{0 . 0 7 1}$ (not significant)

TABLE 4. Prevalence of primate space in upper and lower arches

\begin{tabular}{|c|c|c|c|c|c|c|}
\multirow{2}{*}{ Age } & \multicolumn{2}{c|}{ Primate space(lower arch) } & \multicolumn{3}{c|}{ Primate space (upper arch) } \\
\cline { 2 - 7 } & present & Not present & Total & Present & Not present \\
\hline 3 year & $203(81.2 \%)$ & $47(18.8 \%)$ & 250 & $226(90.4 \%)$ & $24(19.6 \%)$ & 250 \\
4 year & $179(81.4 \%)$ & $41(18.6 \%)$ & 220 & $198(90 \%)$ & $22(10 \%)$ & $18(21.2 \%)$ \\
5 year & $128(80 \%)$ & $32(20 \%)$ & 160 & $142(88.8 \%)$ & $64(10.2 \%)$ & 630 \\
Total & $510(81 \%)$ & $120(19 \%)$ & 630 & $566(89.8 \%)$ &
\end{tabular}

TABLE 5. Prevalence physiological space in upper and lower arches

\begin{tabular}{|c|c|c|c|c|c|c|}
\hline \multirow{2}{*}{ Age } & \multicolumn{2}{|c|}{ Physiological spaces(lower arch) } & \multicolumn{3}{|c|}{ Physiological spaces(upper arch) } & \multirow{2}{*}{ Total } \\
\hline & present & Not present & total & Present & Not present & \\
\hline 3 year & $187(74.8 \%)$ & $63(25.2 \%)$ & 250 & $205(82 \%)$ & $45(18 \%)$ & 250 \\
\hline 4 year & $160(72.7 \%)$ & $60(27.3 \%)$ & 220 & $177(80.5 \%)$ & $43(19.5 \%)$ & 220 \\
\hline 5 year & $114(71.3 \%)$ & $46(28.7 \%)$ & 160 & $134(83.8 \%)$ & $26(16.2 \%)$ & 160 \\
\hline Total & $461(73.2 \%)$ & $169(26.8 \%)$ & 630 & $516(81.9 \%)$ & $114(18.1 \%)$ & 630 \\
\hline
\end{tabular}

$X^{2}=11.73, p=0.098$ (not significant)

\section{DISCUSSION}

It is important to detect early in the primary dentition situations that predispose to develop permanent dentition malocclusion ${ }^{(16)}$. The occurrence of malocclusion begins from the primary dentition, thus it is very important to understand the occlusion, 
as well as the alterations of occlusal pattern during primary dentition period.

The normal molar relation of primary dentition is flush terminal plane until eruption of the permanent first molars $^{17}$. In the present study, most of the children had flush terminal plane molar relation in $69.4 \%$ on right side and $69.8 \%$ on left, which was consistent with the findings of several previous studies in the literature among different population ${ }^{(17-23)}$. However our result support the finding of other investigators ${ }^{(11,24)}$ who stated that mesial step or flush terminal plane molar relation are both normal.

Considering the canine relationship, the most common occlusal relationship in the present study was found to be Class I relation $91 \%$ on right side and $91.7 \%$ on left . The prevalence of Class II canine \& Class III canine relation was $5.7 \%$ \& $3.3 \%$ respectively on right side while the prevalence of Class II canine \& Class III canine relation was $4.6 \%$ \& $3.7 \%$ respectively on left side. The most common canine relationship has been found to be Class I ,which is in agreement with other findings in various ethnic groups ${ }^{(9,19)}$. The prevalence and frequency of Class II \& class III canine relation were consistent with the findings of Qtuyemi et $\mathrm{al}^{(9)}$ but not with the findings of other studies ${ }^{(15,19-21)}$ due to differences in research methods applied in evaluating the prevalence of malocclusion .

The incidence of normal overbite was observed in $67.3 \%$ of children, $0.8 \%$ edge-to-edge, $0.3 \%$ anterior open bite and increased overbite in $31.6 \%$ of the sample comparable with several studies ${ }^{(9,25)}$. No understandable cause could be offered to clarify the difference except the oral habits, such as finger sucking and dummy sucking may act a significant role $^{(9)}$.

In the current study primate spaces were observed in the majority of the kids in the maxillary arch $89.8 \%$ \& less percentage $81 \%$ was registered in the mandibular arch. These results correspond with the findings of previous investigations including Egyptian ,Iranian, Nigerian, Jordanian \& Indian kids where primate spaces was registered more frequent in the upper arch than in the lower arch ${ }^{(7-9,26)}$. But, the prevalence is a slight higher in the present study. These results revealed that the anterior spacing seems to be a normal feature of the deciduous teeth in Iraqi children. The prevalence of physiological spaces in the upper and lower arches were $81.9 \%$ and $73.2 \%$ respectively, which is greater than the results in Jordanian kids where the prevalence of physiological spaces in the upper and lower arches were $61 \cdot 8 \%$ and $61 \cdot 1 \%$ respectively ${ }^{19}$. Nevertheless, generalized incisor spacing in Nigerian kids was exist in low percentage in $44 \%$ of the mandibular arches and $37 \cdot 7 \%$ of the maxillary arches ${ }^{(9)}$. Variance in the prevalence of the physiological and primate spaces in the previous reports may be related to the age difference of the examined children ,ethnical background and environmental factors.

\section{REFERENCES}

1. Bishara SE, Hoppens BJ, Jakobsen JR, Kohout FJ. Changes in the molar relationship between the deciduous and permanent dentitions: a longitudinal study. Am J Orthod Dentofacial Orthop 1988 Jan;93(1):19-28.

2. Rakesh N, Nilima T, Rahul G. Occlusal traits of deciduous dentition of preschool children of Indian children. Contemporary clinical dentistry 2012; 3(4) 443-447

3. Alexander S, Prabhu NT. Profiles, occlusal plane relationships and spacing of teeth in the dentitions of 3 to 4 years old children. J Clin Pediatr Dent 1998 Summer;22(4):329- 334.

4. Foster TD. A textbook of orthodontics. 2nd ed. St Louis: Blackwell Scientific Publications, Mosby Book Distributors; 1982.

5. Moyers RE. Handbook of orthodontics. 3rd ed. Chicago Yearbook Medical Publishers; 1972.

6. Mahduri V, Chandrasekhar R, Vinay C. Occlusal characteristics and spacing in primary dentition:a gender comparative cross sectional study. International Scholarly Research Notice 2014,article ID 512680 , 7 pages.

7. Joshi M, Makhija P. Some observations on spacing in the normal deciduous dentition of 100 Indian children from Gujarat. Br J Orthod. 1984;11(2):75-9

8. Mahmoodian J, Afshar H, Hadjhashem M. Determination Of Primate Space On 4 To 5 Years Old Children Of Tehran's Kindergarten in 2000. J Dent Tehran University of Medical Sciences. 2004;1(1):21-6.

9. Otuyemi O, Sote E, Isiekwe M, Jones S. Occlusal relationships and spacing or crowding of teeth in the dentitions of 3-4-year-old Nigerian children. Int J Paediatr Dent. 1997 Sep;7(3):155-60.

10. Abu Affan A, Abd-Alrahman R. Occlusal Characteristics of Primary Dentition in Sudanese Children in Khartoum State. Braz Dent Sc 2014; 17(2):3-9.

11. Nanda RS, Khan I, Anand R. Age changes in the occlusal pattern of deciduous dentition. J Dent Res. 1973; 52(2): 221-24.

12. Kisling E, Krebs G. Patterns of occlusion in 3-year-old Danish children. Community Dent Oral Epidemiol. 1976; 4(4): $152-59$.

13. Kabue MM, Moracha JK, Ng'ang'a PM. Malocclusion in chil- dren aged 3-6 years in Nairobi, Kenya. East Afr Med J. 1995; 72(4):210-20.

14. Valente A, Mussolino ZM. Frequency of overjet, overbite and open bite in the deciduous dentition. Rev Odontol Univ Sao Paulo. 1989; 3(3):402-07.

15. Ferreira RI, Barreira AK, Soares CD, Alves AC. Prevalence of normal occlusion traits in deciduous dentition. Pesqui Odontol Bras. 2001; 15(1):23-28.

16. Malandris M, Mahoney EK. Aetiology, diagnosis and treatment of posterior cross-bites in the primary dentition. Int J Paediatr Dent 2004;14(3):155-166.

17. Clinch LM: An Analysis of Serial Models Between Three 
and Eight Years of Age. Transactions of the British Society for the Study of Orthodontics 1957:13-31.

18. Infante PF. Malocclusion in the deciduous dentition in white, Black, and Apache Indian children. Angle ortho. 1975; 45: 213-18.

19. Abu Alhaija ES, Qudeimat MA. Occlusion and tooth/arch dimensions in the primary dentition of preschool Jordanian children. Int J Paediatr Dent. 2003 Jul; 13(4):230-39.

20. Farsi NM, Salama FS. Characteristics of primary dentition occlusion in a group of Saudi children. Int J Paediatr Dent. 1996; 6(4):253-59.

21. Yilmaz Y, Gürbüz T, Sim ${ }^{\circ}$ ek S, Dalmi ${ }^{\circ}$ A. Primary canine and molar relationships in centric occlusion in three to six year-old Turkish children: a cross-sectional study. J Contemp Dent Pract. 2006; 7(3):59-66.

22. Zakirulla M. Malocclusion in deciduous dentition of Saudi children: A cross-sectional study. Bangladesh J Med Sci. 2012;11(4):343-6.

23. Baidas L. Occlusion characteristics of primary dentition by age in a sample of Saudi preschool children. Pakistan Oral Dent J. 2010;30(20).

24. Baume LJ. Physiological Tooth Migration and Its Significance for the Development of Occlusion: I. The Biogenetic Course of the Deciduous Dentition. J Dent Res 1950; 29:123-32.

25. Sham S, Ajay H, Sundeep K, Kiran B. Characteristics of Primary Dentition Occlusion in Preschool Children: An Epidemiological Study Int J Paediatr Dent 2012;5(2):9397.

26. Onyeaso CO, Isiekwe MC. Occlusal changes from primary to mixed dentitions in Nigerian Children. Angle Orthod. 2008;78(1):64-69. 